\title{
Happy to take questions
}

\author{
Journals introduce interactive online features that empower readers with the ability to \\ comment on published papers. But readers are slow to seize the opportunity.
}

Thanks to the popularization of social software, sharing programs, blogs and other wikis, a new generation of world-wide web users finally thinks of it as more than a giant library that one consults to retrieve information. The web is becoming a truly participative arena, and the buzzword of the day is 'web 2.0'. Although Nature Methods is clearly not a web 2.0 enterprise, the idea of increased reader participation is nonetheless seductive. Thus we too have created an online space inviting readers' contributions, in particular comments on published papers. We have dubbed the site methagora, hoping that like the ancient Greek agora, it will become a public place where 'citizen readers' assemble and discuss important (methodological) matters.

But the uptake is slow. Of course, these are still early days, and many people may not even be aware of this forum-hence this editorial and upcoming promotion. Other similar initiatives, however, such as those ongoing at Cell and Nature Biotechnology, experience an equally scarce response. Particularly worrisome is the fact that the Nature Biotechnology initiative and one of the methagora postings are seeking community feedback on papers that outline proposed reporting standards. Despite the potential impact that such standards, if adopted, would have on individual researchers, only a handful of the interested have taken the time to comment. This lackluster reaction makes us pause and speculate about scientists' motivations for the commenting activity.

Meanwhile, enterprises with a web 2.0 flavor are sprouting in the life sciences, indicating overall confidence in scientists' eagerness to participate. The boldest of such ventures is the new journal PLoS ONE, which relies on reader comments to filter published information. Besides, scientists count many bloggers among their ranks, and reporters and editors of scientific journals, following the example of their colleagues in the general press, are blogging along. Most bloggers, however, muse on science and society more than they hold technical discussions.

Nature Methods' methagora is not a blog but a commenting forum: the editors suggest discussion topics, usually published papers likely to generate debate, and give the stage to readers-turned-commentators. Our web traffic statistics and informal feedback from the relevant communities indicate that the featured papers have been read by many researchers, ruling out the fact that their lack of visibility is the cause of silence. In fact, we hear that some of the featured papers are generating insightful discussions; but these tend to take place in conference corridors rather than in the meeting rooms and on methagora.

Seemingly, some scientists feel that the commenting forum constitutes a solid enough record to be shy about expressing opinions on topics that will still evolve-thus preferring one-on-one discussions with their peers over public exposure. In contrast, others do not seem to find our online forum legitimate enough. Indeed several researchers have reacted to the featured papers by submitting a Correspondence manuscript for publication in the journal-thus preferring the permanence and legitimacy of the print record to the informal setup of an online forum.

But an online forum is valuable precisely because it provides a complement to the print record, a place in which issues can be discussed rapidly, in an informal way and for the benefit of all. Each reader, regardless of their status, can contribute equally. Anecdotal evidence and personal experience, while they may not be sufficient to justify a formal Article or Correspondence, may be valuable if presented as such in an online forum. It is also a place for concerns about a paper's implications to be voiced in a constructive way. And questions may be as worthy as answers because they provide food for thought to the peer group.

Although we strongly encourage contributors to use their real name and affiliation, to promote transparency, we understand that some researchers, especially those less established, may prefer to remain anonymous. It is also possible that some scientists are reluctant to participate in a public discussion for fear that it could degenerate into an illogical or spiteful exchange. Those can rest assured that editors will moderate the debates to keep them courteous and on topic.

Informed remarks and constructive debate about methodological concepts can impact many researchers, and arguably, comments on methods are overall more useful than comments on biological results. We are confident in this potential benefit and will continue to invite comments on the papers we publish. We encourage you to participate and welcome your feedback on how we can improve methagora (http://blogs.nature.com/nmeth/ methagora/).

After all, this is 'your space'. 